Please quote as: Knote, R.; Söllner, M. \& Leimeister, J. M. (2017): Towards Requirement Patterns for Smart Physical Work Assistants. In: International Workshop on Requirements Patterns (RePa' 17). Lisbon, Portugal. 


\title{
Towards Requirement Patterns for Smart Physical Work Assistants
}

\author{
Robin Knote $^{1}$, Matthias Söllner ${ }^{1,2}$, Jan Marco Leimeister ${ }^{1,2}$ \\ ${ }^{1}$ Reserach Center for Information System Design (ITeG) \\ University of Kassel \\ Kassel, Germany \\ \{robin.knote|soellner|leimeister\}@uni-kassel.de \\ ${ }^{2}$ Institute of Information Management (IWI-HSG)
University of St.Gallen
St.Gallen, Switzerland
\{matthias.soellner|janmarco.leimeister\}@unisg.ch
}

\begin{abstract}
Although physical work is becoming increasingly automated, many tasks in manufacturing, assembly or quality assurance still require human expertise, skills and subjective evaluation. Therefore, digitization offers the possibility to support such physical tasks by smart assistant systems. Being part of a larger research project, the aim of this short paper is to present requirement patterns that have evolved during a case study at a German car component manufacturer. Guided by work design theory, our research reveals four requirement patterns that support requirements specification of smart physical work assistants with regard to autonomy, task variety, task identity and feedback from tasks.
\end{abstract}

Index Terms - software requirement patterns, work design theory, job satisfaction.

\section{INTRODUCTION}

In an increased digitized world, the importance of physical work for economic welfare is often underestimated or becomes forgotten. However, although around $80 \%$ of laborintensive, repetitive tasks conducted in highly predictive environments are likely to be automated in the near future, complex manufacturing tasks are an exception to this rule, since they rely on creative thinking, subjective evaluation or control and maintenance of robots [1]. Hence, advances in information technology (IT) do not only result in a certain degree of automation. They also pave new ways for supporting and facilitating physical work by systems which adapt to (1) a specific task and (2) workers' individual characteristics and working behavior.

Although the importance of supporting physical work is still evident in a digitized environment, few efforts have yet been made to ease the life of, for example, manufacturers and maintainers by 'smart' IT artifacts. As one example, the German car manufacturer Audi has deployed an ergonomic exoskeleton based on robot technology that allows its wearers to sit wherever and whenever they want [2]. The company aims at reducing leg loading and preventing crooked body posture and injuries caused by repeated movements of physical workers. Despite efforts that have been made to reduce physical strain (especially in ergonomics research), supporting physical tasks may also include reducing cognitive load, e.g., by providing context-dependent information and guidance that aid physical task conduction. However, whereas advantages of smart assistants for physical work are obvious, requirements for specifying and developing such systems are not. Given the complexity, variety and individuality of (1) specific physical tasks and (2) workers' characteristics, behaviors and abilities, specifying requirements for Smart Physical Work Assistants (SPWAs) must be considered a highly interdisciplinary endeavor. In more detail, both analytical and design-related knowledge from ergonomics, psychology, jurisprudence, information systems and computer science must be combined and applied purposefully to develop SPWAs capable to handle worker- and task-related complexity. Furthermore, the interpretation of and adaption to different contexts adds a new dimension of complexity to the requirements engineering and systems development process [3].

To reduce complexity and give a starting point for the specification of SPWAs, we introduce requirement patterns that incorporate the name, the goal, forces and a pre-defined requirement template that can be used to formulate requirements in specific development projects. Building up on work design theory (WDT) as a widely used psychological construct to explain antecedents of job satisfaction and individual performance, we conducted requirements elicitation interviews at a German car component manufacturing company that uses three SPWAs for assembly, maintenance and tool management. This approach was chosen based on the consideration that WDT as an analytical framework clearly depicts what to consider in general when striving for job satisfaction and performance whereas interviews make clear how to achieve WDT goals for the specific case of SPWAs. In other words, interview results reveal how WDT antecedents manifest in the specific context and thus are foundational for SPWAs requirement patterns. From 13 interviews with users, a total number of 43 requirements were elicited, of which 18 explicitly address antecedents of the WDT. Ten requirements have recurred across all user groups and systems. We captured these requirements in four requirement patterns according to the antecedents of WDT. These requirement patterns hence portray an operationalization of WDT antecedents and thus serve as supporting instruments for SPWAs requirements specification. Due to the complexity and variety depicted above, the patterns are suggested to (1) help requirements engineers to better understand which design considerations will most likely lead to increased job satisfaction and 
individual performance of workers and (2) specify SPWAs that explicitly account for these outcomes.

This short paper is structured as follows: Section II provides an overview of the WDT and its implications for our study. We elaborate on our research design in Section III and present our results, i.e., the requirement patterns, in Section IV. Our findings are further discussed in Section V. The paper concludes with limitation and next steps in Section VI.

\section{WORK DESIGN THEORY}

Honoring job satisfaction as an important affective attitude to increase job performance, WDT is widely acknowledged to explain how work is accomplished based on work characteristics and in context of the range and nature of tasks associated with a job [4-6]. Prior research found four major antecedents of job satisfaction, namely autonomy, task variety, task identity and feedback from tasks [7]. Autonomy is understood as the degree of self-determinacy and dependency on others when conducting a task [8]. Task variety is referred to as richness, non-monotony and challengingness of tasks and of the entirety of tasks associated with a job [9]. Task identity means the extent to which workers can complete an entire piece of work from the beginning to the end and easily identify its outcome [10,11]. Feedback from tasks reflects the degree to which appropriate, direct and clear information about the individual's effectiveness of task performance is given by the task [6].

In the context of our work, autonomy, task variety, task identity and feedback from tasks reflect how users of SPWAs perceive physical work. Hence, we propose that such systems should empower respective antecedents to increase job satisfaction and individual performance. In other words, WDT describes what should be accomplished when SPWAs are used.

\section{RESEARCH DESIGN}

Based on WDT as a theoretical framework, we conducted requirements elicitation interviews with workers of a German manufacturer and supplier of car components. The company uses three SPWAs for assembly, quality assurance and tool management. System 1 is used in the assembly line for gearbox casings. Five interviewees, including assembly operators and stand-ins, are informed, observed and guided during assembly tasks. The system helps the worker picking required material, rotating and lifting the workpiece and observing tool operations through integrated sensors. More precise, the system gives acoustic feedback when manual mistakes are made (e.g., picking wrong parts) and commits correct task conduction by presenting a smiley at the end of a task. System 2 supports final quality assurance inspection tasks. Four interviewees, all having the role of quality assurance inspectors, are informed, guided and observed in different testing tasks on four testing stations. The system scans an RFID tag to identify the testing unit and, based on respective database information, guides the worker through required measurement steps for quality assurance. Some tools, such as calipers, are enhanced by sensors that transmit measurement data directly to the system core. The system also supports semi-automatic testing procedures. Therefore, it displays how the testing unit and the testing device must be positioned for a particular part before autonomously running the test. Testing tasks range from manual measurement over automated strain tests to final inspection and packaging. System 3 helps tool developers and providers to manage tools across all assembly and maintenance processes. It supports the development, installation and maintenance of production tools by aggregating tool data from different workplaces and offering semantic search, 3D visualization and data editing of a consistent tool data set. The system shows a parts list, current stock and locations from sensor data integrated in respective tools and generates a digital ident sheet which contains all relevant dimensions, properties, parts and cutter data.

In our requirements elicitation interviews, we follow good practices in order to get an in-depth understanding of the requirements and underpinning motivations [12-14]. Being integrated in a larger case study, interviewees were confronted with a consolidated overview of how they evaluate current implementations of SPWAs that they use for conducting their job tasks. This served as a starting point for a discussion about suitable requirements for such systems. The discussion was guided by a semi-structured interview guide according to the four dimensions of WDT (i.e., Autonomy, Task Variety, Task Identity and Feedback from Tasks). Mirroring previous experiences against expectations, the requirements hence reflect what interviewees perceive as good in the respective system and where they see opportunities for improvement. By doing so, 43 requirements were elicited of which 18 explicitly address one or more WDT dimensions. Of these, ten recur across all three cases.

We used these ten requirements as a foundation to follow the opportunistic approach for developing four requirement patterns [15]. First, we formulated the pattern goal to express what should be achieved when the pattern is applied. For our case, it reflects underpinning motivations of user requirements to raise respective WDT antecedents. Incorporating the problem that should be solved by the pattern, the goal is important for requirements engineers to determine whether or not the pattern is applicable to the system at hand [16]. The core of the solution is reflected by the pattern template. It states that the software has to achieve the goal of the requirement pattern but does not necessarily elaborate on how this can be achieved [16]. In our case, the template is written in short sentences and must be adapted to the development context during the process of requirements specification. A concise name was chosen for each pattern to highlight the essence of the template. Finally, the requirement patterns were adapted to the RePa pattern template [17] by adding the RE activity, pattern type, stakeholders and example applications as well as forces that are balanced by the requirements.

\section{RESULTS}

A full list of relevant requirements is presented in Tab. I. 
TABLE I. REQUIREMENTS FOR SPWAS

\begin{tabular}{|l|l|c|}
\hline \multicolumn{1}{|c|}{ ID } & \multicolumn{1}{|c|}{ Requirement Labels } & Systems \\
\hline R1 & Appropriate observation of manual work & $1-3$ \\
\hline R2 & Ergonomic adaption to user characteristics & $1-3$ \\
\hline R3 & Automatic personalized login & $1-3$ \\
\hline R4 & Fail-safe operation & $1-3$ \\
\hline R5 & Easy Self-Help & $1-3$ \\
\hline R6 & Simple Customization & $1-3$ \\
\hline R7 & Various Ways of Working & $1-3$ \\
\hline R8 & Feedback Channel & $1-3$ \\
\hline R9 & Hands-free Interaction & $1-3$ \\
\hline R10 & Mobile Use & $1-3$ \\
\hline R11 & Empowerment for Varied Work & 1,2 \\
\hline R12 & Misentry Suggestion & 1,3 \\
\hline R13 & Information Accuracy & 2,3 \\
\hline R14 & Physical Protection & 1,2 \\
\hline R15 & Seamless Integration & 1,2 \\
\hline R16 & Real-time Feedback & 2 \\
\hline R17 & Controlled Action & 2 \\
\hline R18 & Cooperation & \\
\hline
\end{tabular}

Based on ten recurring (or cross-case) requirements (R1R10) and informed by eight requirements that did not recur across all systems but increase the validity and meaningfulness of the results (R11-R18), four requirement patterns have emerged and were named according to WDT antecedents.

TABLE II. REQUIREMENT PATTERN: AUTONOMY

\begin{tabular}{|c|l|c|}
\hline \multicolumn{2}{|c|}{ Autonomy } \\
\hline $\begin{array}{c}\text { RE Activity: } \\
\text { Elicitation, } \\
\text { Specification }\end{array}$ & \multicolumn{1}{|c|}{$\begin{array}{c}\text { Pattern Type: } \\
\text { Product } \\
\text { (Poal } \\
\text { (Problem) }\end{array}$} & $\begin{array}{l}\text { Satisfy the user need of having a system that allows for } \\
\text { autonomous conduction of tasks. }\end{array}$ \\
\hline Forces & $\begin{array}{l}\text { A tradeoff between the wish for autonomy and the wish } \\
\text { for guidance must be found. High degrees of autonomy } \\
\text { may lead to failures and thus decrease job satisfaction. } \\
\text { A low degree of autonomy may lead to dissatisfaction, } \\
\text { due to low self-determinacy. }\end{array}$ \\
\hline $\begin{array}{c}\text { Template } \\
\text { (Solution) }\end{array}$ & $\begin{array}{l}\text { The system should provide for information and } \\
\text { guidance to enable workers to conduct tasks by } \\
\text { themselves. }\end{array}$ \\
\hline \multicolumn{3}{|c|}{$\begin{array}{c}\text { Application and Examples } \\
\text { The system provides information about a specific workpiece, steps } \\
\text { required or components and tools needed for the respective task. It } \\
\text { further provides step-by-step guidance for a task. Help should be } \\
\text { activated/deactivated by the worker to establish control over the } \\
\text { desired degree of autonomy. }\end{array}$} \\
\hline
\end{tabular}

The first requirement pattern addresses the workers desire for autonomously performing tasks (Tab. II). Establishing the right level of autonomy is a complex endeavor, since getting the balance right between autonomy and guidance is highly dependent on individual characteristics and attitudes: Whereas some workers enjoy self-determinant and flexible work, others, especially unexperienced workers, wish stepby-step guidance for the task at hand.
TABLE III. REQUIREMENT PATtERN: TASK VARIETY

\begin{tabular}{|c|l|c|}
\hline \multicolumn{2}{|c|}{ Task Variety } \\
\hline $\begin{array}{c}\text { RE Activity: } \\
\text { Elicitation, } \\
\text { Specification }\end{array}$ & \multicolumn{1}{|c|}{\begin{tabular}{c}
\multicolumn{1}{|c|}{ Pattern Type: } \\
Product
\end{tabular}} & \multicolumn{1}{c|}{$\begin{array}{c}\text { Stakeholders: } \\
\text { Users }\end{array}$} \\
\hline $\begin{array}{c}\text { Goal } \\
\text { (Problem) }\end{array}$ & $\begin{array}{l}\text { Satisfy the user need of having a system that allows for } \\
\text { variety in monotonous tasks. }\end{array}$ \\
\hline Forces & $\begin{array}{l}\text { Balancing flexibility and controlled processes highly } \\
\text { depends on users' experiences. Whereas unexperienced } \\
\text { users wish clear guidelines on how to conduct a } \\
\text { specific tasks, experienced users tend to actively search } \\
\text { for alternative ways (e.g., cooperating with others). }\end{array}$ \\
\hline $\begin{array}{c}\text { Template } \\
\text { (Solution) }\end{array}$ & $\begin{array}{l}\text { The system should provide for various ways for } \\
\text { conducting tendentially monotonous tasks, both alone } \\
\text { and with colleagues. }\end{array}$ \\
\hline
\end{tabular}

\section{Application and Examples}

The system offers the opportunity to select alternative task processes. Processes should not differ in terms of effort and time. Tasks should explicitly enable cooperation with co-workers where appropriate.

Physical tasks are repetitive to some degree and are often perceived as monotonous in the long term. However, overcoming task-related barriers that impede various work is nearly impossible without organizational adjustments. Hence, alternatively task variety can be achieved through offering various ways of working (Tab. III). Workers can either follow the default process or choose a process alternative. Process alternatives may include cooperative activities where appropriate.

TABLE IV. REQUiREMENT PATtern: TASK IDENTITY

\begin{tabular}{|c|l|c|}
\hline \multicolumn{3}{|c|}{ Task Identity } \\
\hline $\begin{array}{c}\text { RE Activity: } \\
\text { Specifitionion }\end{array}$ & \multicolumn{1}{|c|}{$\begin{array}{c}\text { Pattern Type: } \\
\text { Product }\end{array}$} & \multicolumn{1}{c|}{$\begin{array}{c}\text { Stakeholders: } \\
\text { Users }\end{array}$} \\
\hline $\begin{array}{c}\text { Goal } \\
\text { Problem) }\end{array}$ & $\begin{array}{l}\text { Satisfy the user need of identifying with the piece of } \\
\text { work that is conducted. }\end{array}$ \\
\hline Forces & $\begin{array}{l}\text { Work processes are often chunked into different tasks } \\
\text { and conducted by workers with different skills and } \\
\text { responsibilities. While systems may not overcome } \\
\text { these task-related barriers, identity should be } \\
\text { accomplished through personalization and self-help } \\
\text { mechanisms. }\end{array}$ \\
\hline $\begin{array}{c}\text { Template } \\
\text { (Solution) }\end{array}$ & $\begin{array}{l}\text { The system should provide personalized access and } \\
\text { self-help options according to the worker's individual } \\
\text { skillset and responsibilities. }\end{array}$ \\
\hline \multicolumn{1}{|c|}{ Application and Examples } \\
The system provides for personalized login, customizable UI elements \\
and ergonomic adaption of connected physical components (e.g., \\
workbenches automatically lift to the optimal height for an individual \\
user). In case of problems, users can help themselves through step-by- \\
step solution descriptions
\end{tabular}

Similar to task variety, task identity usually requires organizational adaption so that workers can conduct a piece of work from the beginning to the end and identify its results. However, task identity also refers to a degree of familiarity with the task and the technology, which can be accomplished by personalization and ergonomic adaption to workers' preferences (Tab. IV) [18]. 
TABLE V. ReQuirement PATtern: FEEDback From TASKS

\begin{tabular}{|c|l|c|}
\hline \multicolumn{2}{|c|}{ Feedback from Tasks } \\
\hline $\begin{array}{c}\text { RE Activity: } \\
\text { Specificion, }\end{array}$ & \multicolumn{1}{c|}{$\begin{array}{c}\text { Pattern Type: } \\
\text { Product }\end{array}$} \\
\hline $\begin{array}{c}\text { Goal } \\
\text { (Problem) }\end{array}$ & $\begin{array}{l}\text { Satisfy the user need of receiving immediate feedback } \\
\text { from a currently conducted task. }\end{array}$ \\
\hline Forces & $\begin{array}{l}\text { Autonomous feedback can only be given when tasks } \\
\text { are autonomously observed by the system. Hence, users } \\
\text { may have privacy concerns and appropriate observation } \\
\text { of physical tasks must be ensured. Furthermore, } \\
\text { feedback may not be recognizable for co-workers to } \\
\text { avoid social pressure. }\end{array}$ \\
\hline $\begin{array}{l}\text { Template } \\
\text { (Solution) }\end{array}$ & $\begin{array}{l}\text { The system should observe physical tasks and provide a } \\
\text { signal to the user in case of manual mistakes. }\end{array}$ \\
\hline $\begin{array}{l}\text { Application and Examples } \\
\text { The system observes manual tasks through optical recognition devices } \\
\text { (e.g., light barriers, cameras). A gentle signal is given in case the } \\
\text { system recognizes a mistake. In addition, help text is offered on how to } \\
\text { resolve the mistake and correctly conduct the task. }\end{array}$ \\
\hline
\end{tabular}

Providing feedback on task performance can only be accomplished when tasks are observed (e.g., through sensors and cameras) and patterns for 'right' and 'wrong' are implemented in the system and can reliably be recognized. Giving feedback, however, is important, especially for unexperienced workers, to gently draw attention to manual mistakes and give the opportunity to correct them.

\section{DISCUSSION}

The patterns were developed while investigating users' evaluation of SPWAs in the context of assembly, quality assurance and tool management. Hence, we expect that the patterns work best in these contexts. However, the patterns can easily be adopted to other contexts where IT is used to facilitate and support work.

Our patterns can help requirements engineers to address the basic notion of work support for physical tasks and have a starting point for system specification. However, our patterns do not replace a thorough requirements analysis to fully capture the peculiarities of the development project. They rather serve as guidance as they depict which aspects should be addressed, show potential pitfalls and provide initial knowledge for further analysis.

\section{CONCLUSION}

In this paper, four requirement patterns for SPWAs were introduced, namely Autonomy, Task Variety, Task Identity and Feedback from Tasks. With the help of these software requirement patterns, we want to give requirements analysts an easy-to-use approach for specifying work assistance systems according to workers' individual preferences and characteristics. We hence increase the chance of the system to be adopted and continuously used by workers and to consequently increase job satisfaction and individual performance $[19,20]$.

In future research, our requirement patterns will be evaluated in different application contexts in order to prove their applicability and refine them according to evaluation results.
Further development includes parametrization of the requirements template to simplify adoption of the patterns to specific development contexts. Utility will further be enhanced by integrating them into an existing requirement pattern catalog.

\section{ACKNOWLEDGMENT}

Our research was thankfully sponsored by the Deutsche Forschungsgemeinschaft (DFG; ref. LE 2422/2-1), the selfgoverning organization for science and research in Germany.

\section{REFERENCES}

[1] McKinsey, What's now and next in analytics, AI, and automation, available at http://www.mckinsey.com/globalthemes/digital-disruption/whats-now-and-next-in-analyticsai-and-automation?cid=eml-web (accessed on May 15, 2017).

[2] Audi, Chairless Chair for improved ergonomics in Audi's production plants, available at https://www.audimediacenter.com/en/press-releases/chairless-chair-forimproved-ergonomics-in-audis-production-plants-392 (accessed on May 29, 2017).

[3] J. Pascoe, N. Ryan, D. Morse, Issues in Developing ContextAware Computing, Proceedings of the 1st International Symposium on Handheld and Ubiquitous Computing (1999) 208-221.

[4] F.P. Morgeson, S.E. Humphrey, The Work Design Questionnaire (WDQ): developing and validating a comprehensive measure for assessing job design and the nature of work, Journal of applied psychology 91 (6) (2006) 1321.

[5] F. Herzberg, B. Mausner, B.B. Snyderman, The motivation to work, Transaction publishers, 2011.

[6] J.R. Hackman, G.R. Oldham, Motivation through the design of work: Test of a theory, Organizational behavior and human performance 16 (2) (1976) 250-279.

[7] J.B. Thatcher, L.P. Stepina, R.J. Boyle, Turnover of information technology workers: Examining empirically the influence of attitudes, job characteristics, and external markets, Journal of Management Information Systems 19 (3) (2002) 231-261.

[8] Y. Fried, G.R. Ferris, The validity of the job characteristics model: A review and meta-analysis, Personnel psychology 40 (2) (1987) 287-322.

[9] E.G. Lambert, N.L. Hogan, S.M. Barton, The impact of job satisfaction on turnover intent: a test of a structural measurement model using a national sample of workers, The Social Science Journal 38 (2) (2001) 233-250.

[10] H.P. Sims, A.D. Szilagyi, R.T. Keller, The measurement of job characteristics, Academy of Management Journal 19 (2) (1976) 195-212.

[11] S. Ang, S.A. Slaughter, Work outcomes and job design for contract versus permanent information systems professionals on software development teams, Mis Quarterly (2001) 321350.

[12] K. Pohl, Requirements engineering: Fundamentals, principles, and techniques, Springer, Heidelberg, New York, 2010.

[13] C. Rupp, Requirements-Engineering und -Management: Aus der Praxis von klassisch bis agil, 6th ed., Hanser, München, 2014. 
[14] G. Kotonya, I. Sommerville, Requirements engineering: Processes and techniques, J. Wiley, Chichester, New York, 1998.

[15] S. Withall, Software requirement patterns, Microsoft Press, Redmond, Wash., 2007.

[16] S. Renault, O. Mendez-Bonilla, X. Franch, C. Quer, A pattern-based method for building requirements documents in call-for-tender processes, International Journal of Computer Science \& Applications 6 (5) (2009) 175-202.

[17] L. Chung, B. Paech, L. Zhao, L. Liu, S. Supakkul, RePa Requirements Pattern Template, International Workshop on Requirements Patterns (RePa) (2012).

[18] S.Y.X. Komiak, I. Benbasat, The effects of personalization and familiarity on trust and adoption of recommendation agents, Mis Quarterly (2006) 941-960.

[19] V. Venkatesh, H. Bala, Technology Acceptance Model 3 and a Research Agenda on Interventions, Decision Sciences 39 (2) (2008) 273-315.

[20] B.H. Wixom, P.A. Todd, A Theoretical Integration of User Satisfaction and Technology Acceptance, Information Systems Research 16 (1) (2005) 85-102. 